\title{
Stellar Neuroretinitis as Presenting Sign of Behcet's Disease
}

Wafae Jouidi ${ }^{*}$, Karim Lalaoui Moutarajji, Elhassan Abdellah, Amina Berraho

Ophthalmology B department, Avicenne's CHU of Rabat, Mohammed V University, Rabat, Morocco

DOI: $10.36347 /$ sjams.2020.v08i12.006

| Received: 25.11.2020 | Accepted: 04.12.2020 | Published: 10.12.2020

*Corresponding author: Wafae JOUIDI

Abstract

Stellar neuroretinitis is the association of papillary edema with stellate macular exudates. Its differential diagnosis are multiple dominated in the young subject by infectious pathologies. Behçet's disease being one of the rare causes.

Keywords: Neuroretinitis, Behçet, Stellar macular exudates.

Copyright $\odot 2020$ The Author(s): This is an open-access article distributed under the terms of the Creative Commons Attribution 4.0 International License (CC BY-NC 4.0) which permits unrestricted use, distribution, and reproduction in any medium for non-commercial use provided the original author and source are credited.

\section{ObServation}

A 40-year-old One-eyed patient (right eye) acuity history of post-traumatic burst in his left eye at the age of 6 years. Consult for a decrease of vision on his right eye that has progressed for 3 weeks. Ophthalmic examination found visual acuity: 2/10 P10 in the right eye, the left eye presents enophthalmos with an opacified cornea; the anterior segment was normal in the right eye, fundus examination shows hyalitis graded $1+$, papillary edema, peripapillary hemorrhages and stellar macular exudates, cottony nodules, copper arteries with vascular sheathing of the superior temporal branch and areas of retinal ischemia (Figure 1). The inflammatory and serological assessment is negative. Fluorescein retinal angiography shows papillary diffusion of fluorescein and vasculitis (Figure 2). We find serous retinal detachment on OCT (Figure 3). The general examination found bipolar aphthosis. The diagnosis of Behçet's disease is retained. Treatment with immunosuppressants allowed the regression of papillary edema with persistence of some macular exudates and great improvingin visual acuity.

\section{DisCUSSION}

Neuroretinitis can be due to several diseases; infectious diseases being the most frequent in young subjects $[1,2]$. More rarely, the inflammatory origin especially Behçet's disease-can produce neuroretinitis which is more frequently accompanied by a vitreous reaction [2, 3]. Behçet's disease is an idiopathic systemic inflammatory disease characterized by intraocular inflammation, oral and genital ulcers, skin lesions and many other visceral damage [4]. Ocular involvement is characterized by anterior hypopionic uveitis, posterior involvement being rarer, especially if it is isolated, which is the case in our patient $[5,6]$. OCT is used to check for posterior segment edema and /or Serious Retinal DDetachment. Retinal angiography has a threefold benefit: confirming papillary edema, directing towards its ischemic or inflammatory aetiology and looking for vasculitis. The treatment of Behçet's disease is controversial between corticosteroid therapy and immunosuppressants. The prognosis depends on the speed and precocity of the treatment, making collaboration between ophthalmologists and internists particularly important [7]. 


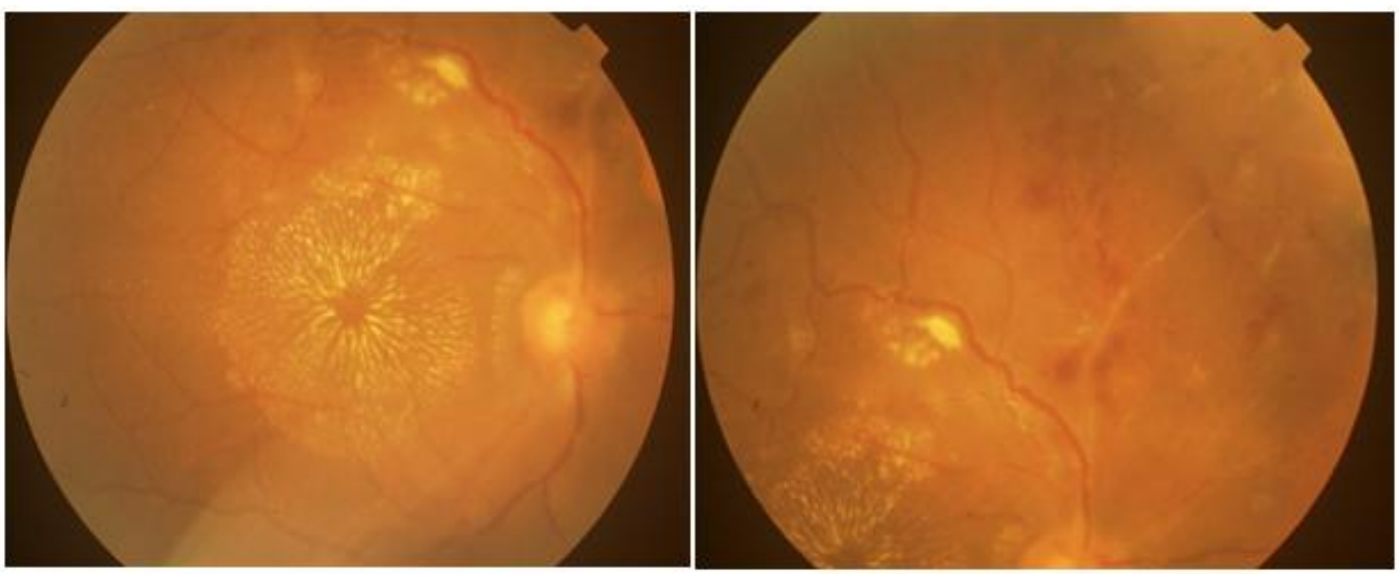

Fig-1: Fundus (Right eye) shows: Left: neuroretinitis. Right: occlusive vasculitis

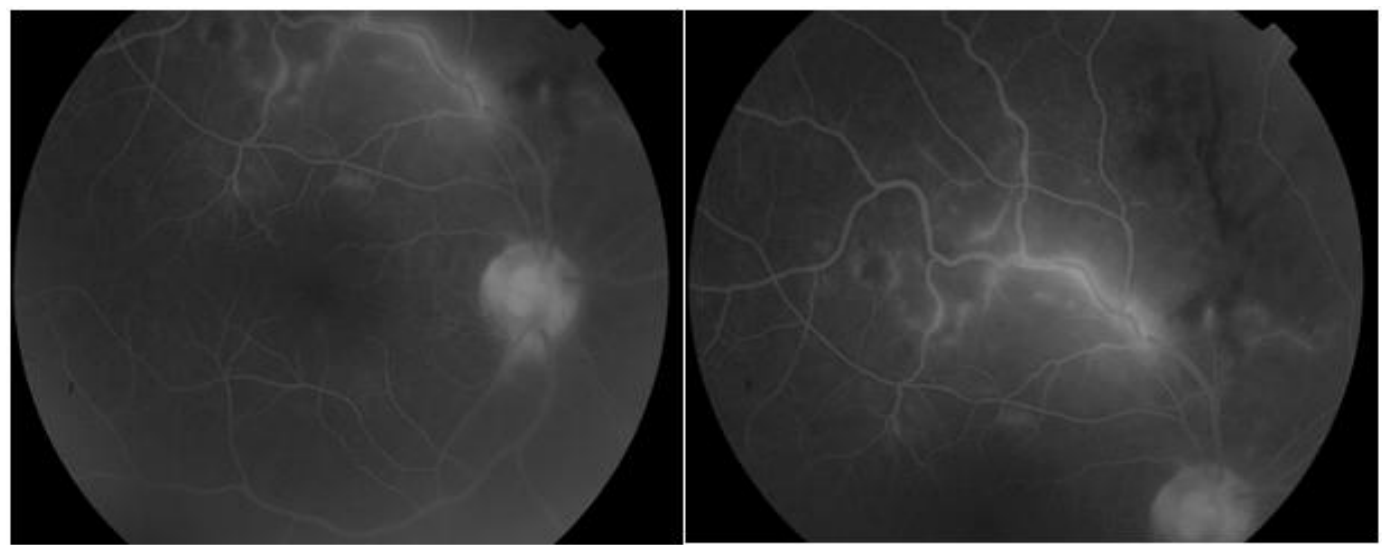

Fig-2: Retinal angiography with fluorescein in late stages: on the left: papillary diffusion. on the left Right: vasculitis with vascular occlusion

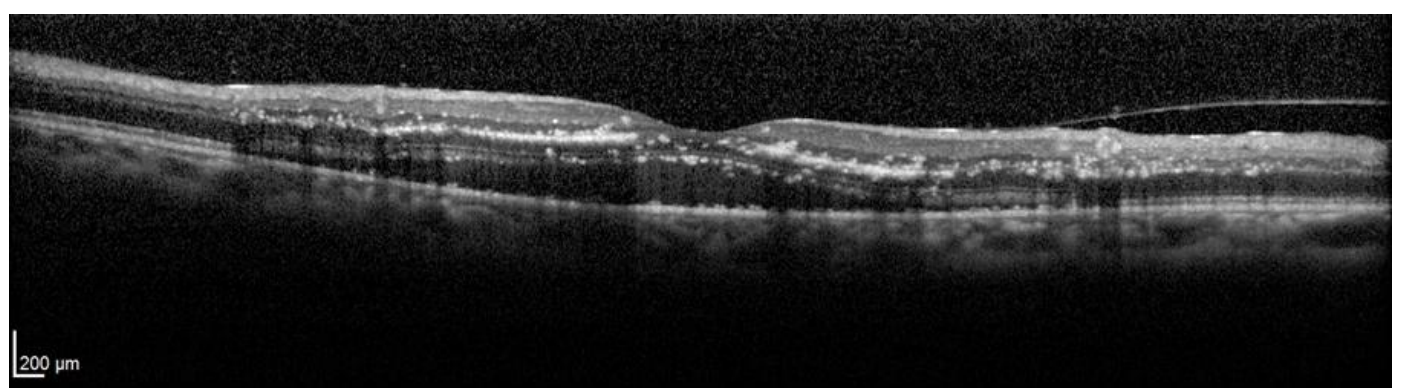

Fig-3: optical coherence tomography (OCT): macular exudates especially at the level of the outer plexiform layer; serous retinal detachment

\section{REFERENCES}

1. Leavitt JA, Pruthi S, Morgenstern BZ. Hypertensive retinopathy mimicking neuro retinitis in a twelve-year-old girl. Surv Ophthalmol 1997; 41(6):477-80.

2. Guyomard JL, Jacob H, Roche O, PierreKahn V, Charlin JF. Présentation d'un cas atypique de rétinopathie hypertensive maligne chez une fi llette. J Fr Ophtalmol. 2004;27(1):57-62.

3. Esteve C, Achibet AM, Junot F, Ghassemi A, Rousseau B. À propos d'un cas de neurorétinite aiguë de Leber. J Fr Ophtalmol. 2000;23(8):794-6.
4. Shimizu T. Behçet's syndrome-Lists of clinical and epidemical statistics. Nihon Rinsho. 1974 Jul 1; 32:2093-102.

5. Michelson JB, Chisari FV. Behçet's disease. Surv Ophthalmol. 1982 Jan-Feb;26(4):190-203.

6. Atmaca LS. Fundus changes associated with Behçet's disease. Graefes Arch Clin Exp Ophthalmol. 1989;227(4):340-4

7. Alami A, Kriet M, Reda K, Laktaoui A, Oubaaz A. Behçet oculaire [Ocular Behçet]. Pan Afr Med J. 2017;26:237. Published 2017 Apr 25. 